\title{
Enhancement of Mechanical Property of Concrete Structure Using the Macro and Micro Steel Fibers
}

\author{
Hyeok Jung Kim¹, Nam Wook Kim², * \\ ${ }^{1}$ Industry-Academic Cooperation Foundation Center, Hankyong National University, Anseong, Republic of Korea \\ ${ }^{2}$ Department of Civil Engineering, Jeonnam State University, Damyang, Republic of Korea
}

Email address:

nwkim@dorip.ac.kr (N. W. Kim)

${ }^{*}$ Corresponding author

\section{To cite this article:}

Hyeok Jung Kim, Nam Wook Kim. Enhancement of Mechanical Property of Concrete Structure Using the Macro and Micro Steel Fibers. American Journal of Civil Engineering. Vol. 8, No. 1, 2020, pp. 1-9. doi: 10.11648/j.ajce.20200801.11

Received: January 7, 2020; Accepted: January 27, 2020; Published: February 18, 2020

\begin{abstract}
Hybrid fiber reinforcement with both macro and micro steel fibers in the concrete matrix is applied in order to evaluate its effectiveness for crack arresting. One of the main objectives of this research is to establish a crack-free high performance concrete. In severe conditions, which may require high water tightness, such as a storage structure for low-level radioactive waste, crack-free high performance concrete structures could be applied. Hybrid fiber reinforcement is well known because it can show excellent performance with a suitable combination of fibers. In this study which deals with hybrid fiber reinforced concrete made with different fiber lengths and fiber contents, the factors which quantify crack resistance of concrete, mainly the first crack strength, flexural strength and strain energy release rate are examined. In this research, the crack resistance of concrete was investigated using the notched specimen by the 4-point bending test for the fiber reinforced concrete and hybrid fiber reinforced concrete (adding the macro and micro fibers). The general conclusions obtained are as follows. To the investigation of the crack resistance of concrete, we obtained the new theoretical equation of the critical strain energy release rate for the hybrid fiber reinforced concrete, and a deep correlation between experimental value and theoretical value was shown. Though in this research, total fiber contents $2.5 \%$ showed the maximum values in the strength and crack resistance, an investigation of the totally mechanical behavior needs more widely range of experiment.
\end{abstract}

Keywords: Enhancement, Mechanical Property, Macro and Micro Fibers, First Crack, Strain Energy Release Rate

\section{Introduction}

Cracks occurring in concrete structures was be due to 1) micro flaws between the cement matrix and aggregate, 2) micro cracks caused by drying shrinkage or 3 ) macro cracks due to the applied load. Concrete eventually fail due to the propagation of cracks [1]. For industrial waste disposal facilities and storage structures for low level radioactive wastes, a low permeability and highly watertight concrete is required. It is therefore essential to control the micro cracks both at early ages and also in the long term. The aim of this research is to examine the crack resistance of hybrid fiber reinforced concrete using a combination of macro-steel fibers and micro-steel fibers. Recently, as the concrete structures are becoming bigger, higher, longer and more special, high strength and performance concrete is demanded, But the fracture behavior of high strength concrete is shown more brittle than that of the normal concrete. Therefore, in order to improve the brittle fracture behavior and crack propagation resistance, ACI Committee-363 has been recommend the use of fiber reinforced concrete which showed superior property against the crack propagation resistance. Usually, the tensile strength of concrete (as induced for thermal stresses in mass concrete) is used to estimate the crack resistance. However, in this research, from the viewpoint of fracture mechanics, the crack resistance was estimated by the strain energy release rate, using the elastic modulus to determine the deformation behavior as well as the tensile strength. Since the 1970`s, fiber reinforced concrete (FRC) has been widely used in construction for the improvement of the flexural and 
tensile strengths of concrete [2]. Usually, the name FRC implies concrete reinforced with only one kind of fiber (e.g. steel fibers, glass fibers, carbon fibers). Recently, hybrid fiber reinforced concrete (HFRC), i.e., fiber concrete using 2 kinds of fibers has attracted special attention [3-4]. One of the advantages of hybrid fiber reinforcement is that reinforcing effects can be obtained by a suitable combination of fibers [5-6].

This research, was aimed at the improvement of concrete durability concerned with regard to water-tightness by the control of first crack initiation (cracks initiated at early stages under loading), by the addition of a combination of macro and micro steel fibers [7-8]. The effects of different contribution of fibers of different lengths on the strength and strain energy release rate are discussed [9-10].

\section{Experimental Outlines}

\subsection{Experimental Plan}

In this research, to compare the reinforcing effects of macro and micro fibers their combinations (that is hybrid FRC), 3 series of specimens were made. These are 1) SF-30, reinforced by $30 \mathrm{~mm}$ macro steel fibers (FRC), 2) SF-6, reinforced by 6 $\mathrm{mm}$ micro steel fibers (FRC), and 3) SF30-SF6, reinforced by a combination of macro and micro steel fibers (HFRC) $[5,9]$ For the macro-fiber FRC's, the fiber contents were ranged from $0.0 \%$ to $2.0 \%$. For the micro-fiber FRC's, the fiber contents ranged from $0.1 \%$ to $2.0 \%$. For the HFRC, a few combinations of fiber were, during total fiber contents increase $1.0 \%$ to $3.0 \%$. As seen in Table 1,18 series of specimens (including one of plain concrete) were produced in total.

Table 1. Specimen types.

\begin{tabular}{llll}
\hline Specimen & Series & Kinds of fibers & Fiber contents (\%) \\
\hline S30-V05 & & & 0.5 \\
S30-V10 & SF30 & Macro steel fiber (30mm) & 1.0 \\
S30-V15 & & & 1.5 \\
S30-V20 & & & 2.0 \\
S6-V01 & & & 0.1 \\
S6-V03 & SF6 & Micro steel fiber & 0.3 \\
S6-V05 & & $(6 \mathrm{~mm})$ & 0.5 \\
S6-V10 & & & 1.0 \\
S6-V15 & & & 1.5 \\
S6-V20 & & & 2.0 \\
S30-S6-V10 & Macro steel fiber & $1.0(0.5+0.5)$ \\
S30-S6-V11 & + & $1.1(1.0+0.1)$ \\
S30-S6-V13 & Micro steel fiber & $1.3(1.0+0.3)$ \\
S30-S6-V15 & & $1.5(1.0+0.5)$ \\
S30-S6-V20 & SF30-SF6 & & $2.0(1.0+1.0)$ \\
S30-S6-V25 & & ---- & $2.5(1.0+1.5)$ \\
S30-S6-V30 & & & $3.0(1.0+2.0)$ \\
P0 & & & 0 \\
\hline
\end{tabular}

The cement type was ordinary portland cement (OPC). River sand and crushed stones were used. Also, for obtaining the workability of HFRC, using superplasticizer, the slump was maintained at $10 \pm 2 \mathrm{~cm}$, and the air was controlled by $5 \%$. A polycarbonic acid superplasticizer was used, and the amount used was below $1.3 \%$ of cement weight. The aspect ratio $(1 / \mathrm{d})$ is 60 for the macro and micro steel fibers each. The characteristics of fibers and materials used in this research are shown in Table 2 and Table 3, respectively.

\subsection{Experimental Plan}

A static 4-point bending test was conducted using beam specimens of $100 \times 100 \times 400 \mathrm{~mm}$ on a span of $300 \mathrm{~mm}$. The load was applied continuously at a rate of $0.2 \mathrm{~mm} / \mathrm{min}$. By using a linear variable displacement transducer (LVDT), the deflection was measured at the center of the specimen. Also, the crack mouth opening displacement (CMOD) was measured at the center edge of specimen with notch (depth/specimen height $=0.3$ ) by using a clip-gauge.

The first crack and the strain energy release rates were obtained from the load deflection curves of the 4-point bending test results. The dimensions of specimen and the experimental apparatus used in this research is shown in Figure 1.

Table 2. Physical characteristics of used materials.

\begin{tabular}{lllll}
\hline Materials & Cement & Fine aggregate & Coarse aggregate & Superplasticizer \\
\hline Kinds & Ordinary portland cement (OPC) & River sand & Crushed stone & Polycarbonic acid type \\
Specific ratio & 3.15 & 2.67 & 2.75 & 1.05 \\
Specific area & $3315 \mathrm{~cm}^{2} / \mathrm{g}$ & ---- & ---- & ---- \\
Fineness modulus & ---- & 2.73 & 6.82 & ---- \\
\hline
\end{tabular}


Table 3. Physical characteristics of used fibers.

\begin{tabular}{llllll}
\hline Kinds of fibers & Length $(\mathbf{m m})$ & Shape & Elastic modulus $\left(\mathbf{N} / \mathbf{m m}^{2}\right)$ & $\begin{array}{l}\text { Tensile strength }\left(\boldsymbol{\sigma}_{\mathbf{f b}}\right) \\
\left(\mathbf{N} / \mathbf{m m}^{2}\right)\end{array}$ & $\begin{array}{l}\text { Bonding strength }\left(\boldsymbol{\tau}_{\mathbf{f b}}\right) \\
\left(\mathbf{N} / \mathbf{m m}^{2}\right)\end{array}$ \\
\hline Steel fibers & 6,30 & Crimped and curled & 192,000 & 750 & 7.5 \\
\hline
\end{tabular}

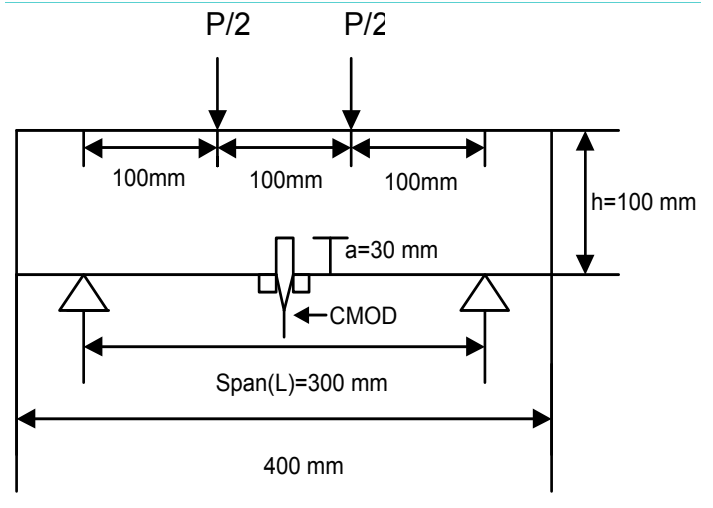

Figure 1. Dimensions of specimen.

\section{Experimental Results and Discussions}

\subsection{Load-deflection Curves and Load-CMOD Curves}

The load-deflection curves and load-CMOD curves of specimens with total fiber contents of $1.0 \%, 1.5 \%, 2.0 \%$ and plain concrete are shown in Figures 2 and 3. As seen in Figures 2 and 3, plain concrete shows a brittle behavior and experiences rapid fracture after reaching the maximum load. In contrast, when FRC reaches the maximum load, cracks propagate slowly. Usually, when there is an increase in the fiber content, there will also be an increase in the first crack strength and flexural strength, and a small decrease in the overall strength beyond the maximum load. Fibers contribute to the toughness of concrete by their bridging action, and because of this FRC do not fracture rapidly after the maximum load. For the same total fiber contents, HFRC increased the toughness (calculated from the load-deflection curves) after maximum load. The effective toughness of HFRC was enhanced by the hybrid effect than. When the fiber contents from $1.5 \%$ to $2.0 \%$, there was no further increase in the maximum load, but the toughness for the SF30 and SF6 specimen (single fiber FRC's) was increased. For the HFRC (SF30-SF-6), the first crack strength and flexural strength increased.

\subsection{Results of First Crack Strength and Flexural Strength}

The results of first crack strength $\left(\sigma_{f c r}\right)$ and flexural strength $\left(\sigma_{f u}\right)$ of each series are shown in Table 4 . The first crack strength and flexural strength of each series were calculated from the first crack load and maximum load obtained from the load-deflection curves. The load at first crack is the point at which the slope changes in the loaddeflection curves. However, it was very difficult to detect the first crack load. The load-deflection curves were called in a logarithm form with the vertical axis LogP, and the horizontal axis deflection $\log \delta$.

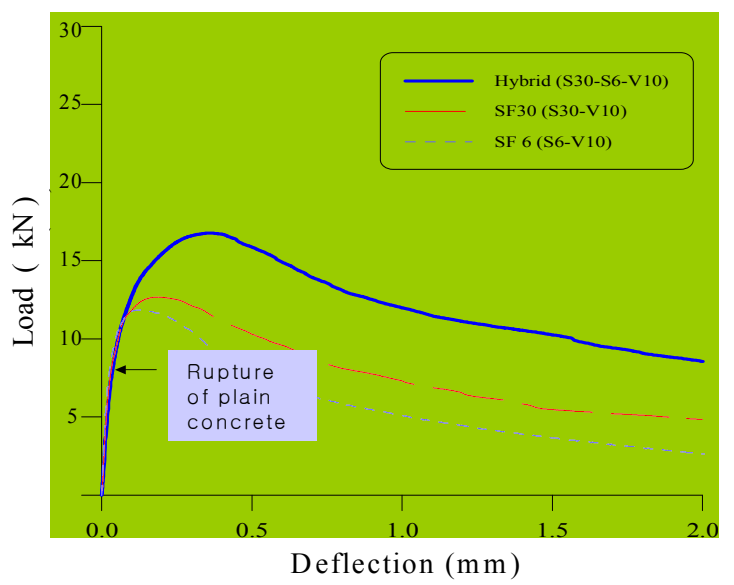

(a) $\mathrm{V}_{\mathrm{f}}=1.0 \%$

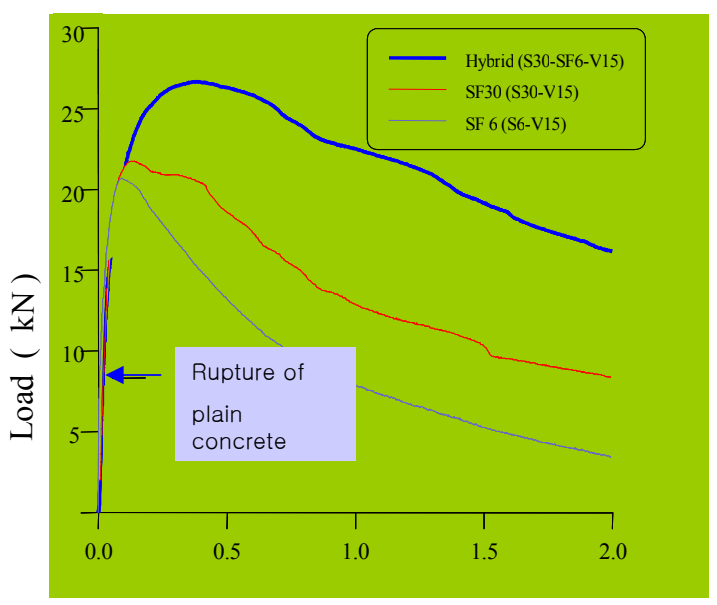

Deflection (mm)

(b) $\mathrm{V}_{\mathrm{f}}=1.5 \%$

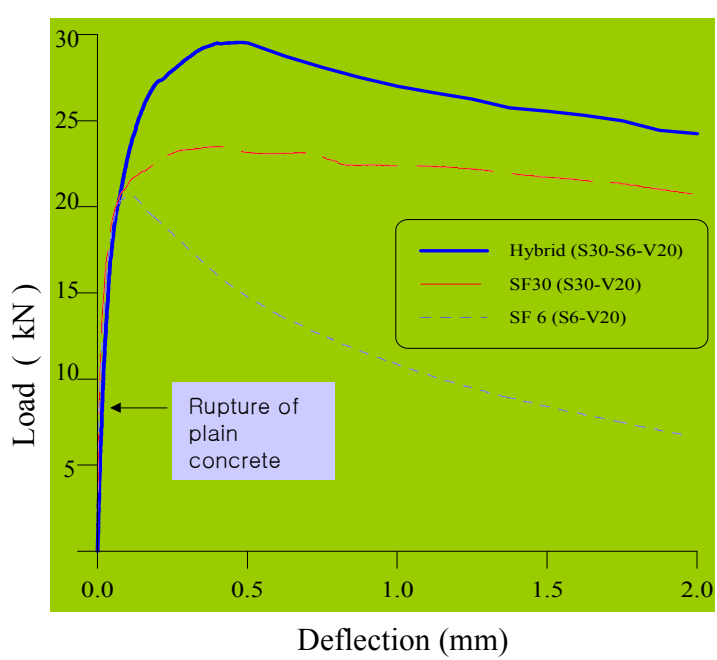

(c) $\mathrm{V}_{\mathrm{f}}=2.0 \%$

Figure 2. Load-Deflection curves. 


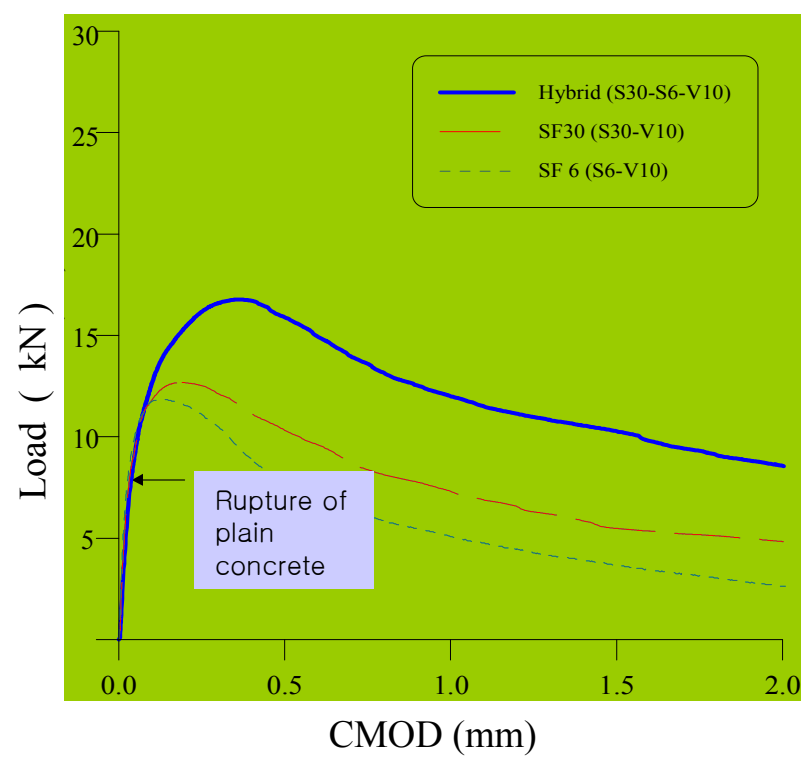

(a) $\mathrm{V}_{\mathrm{f}}=1.0 \%$

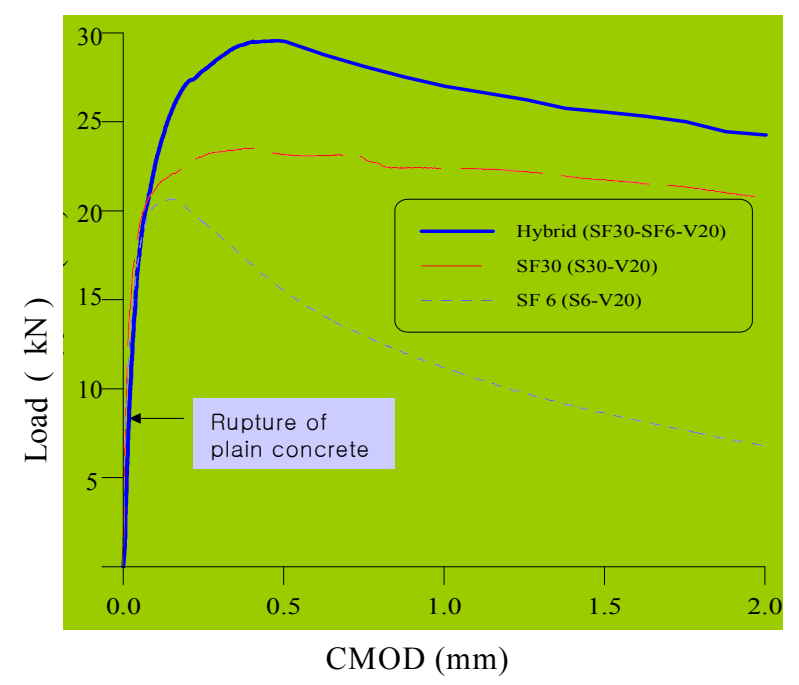

(b) $\mathrm{V}_{\mathrm{f}}=1.5 \%$

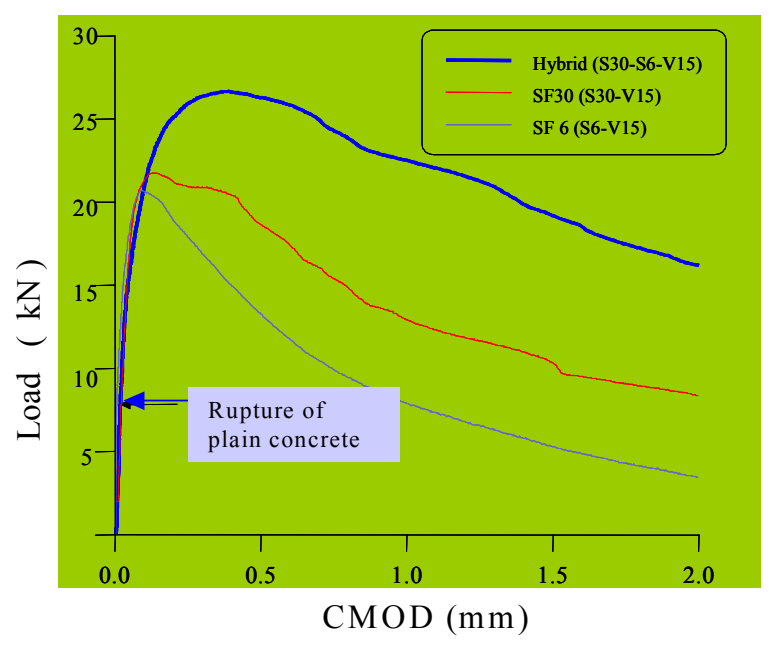

(c) $\mathrm{V}_{\mathrm{f}}=2.0 \%$

Figure 3. Load-CMOD curves.
Table 4. Results of first crack and flexural strength of each series.

\begin{tabular}{llllll}
\hline Specimen & \multirow{2}{*}{ Series } & $\begin{array}{l}\boldsymbol{\sigma}_{\mathbf{f c r}}^{*} \\
\left(\mathbf{N} / \mathbf{m m}^{2}\right)\end{array}$ & $\boldsymbol{\sigma}_{\mathbf{f c r}} / \boldsymbol{\sigma}_{\mathbf{C P}} \mathbf{p *}^{* *}$ & $\begin{array}{l}\boldsymbol{\sigma}_{\mathbf{f u}} \\
\left(\mathbf{N} / \mathbf{m m}^{2}\right)\end{array}$ & $\boldsymbol{\sigma}_{\mathbf{f u}} / \boldsymbol{\sigma}_{\mathbf{B P}}{ }^{* *}$ \\
\hline S30-V05 & & 3.31 & 1.49 & 4.27 & 1.70 \\
S30-V10 & \multirow{2}{*}{ SF30 } & 3.88 & 1.75 & 6.18 & 2.46 \\
S30-V15 & & 4.45 & 2.01 & 6.65 & 2.65 \\
S30-V20 & & 5.07 & 2.28 & 8.15 & 3.25 \\
S6-V01 & & 2.65 & 1.19 & 3.11 & 1.24 \\
S6-V03 & & 3.12 & 1.41 & 3.34 & 1.33 \\
S6-V05 & \multirow{2}{*}{ SF6 } & 3.53 & 1.59 & 3.78 & 1.51 \\
S6-V10 & & 4.67 & 2.10 & 4.79 & 1.91 \\
S6-V15 & & 4.85 & 2.18 & 5.50 & 2.19 \\
S6-V20 & & 5.68 & 2.56 & 6.78 & 2.70 \\
S30-S6-V10 & & 3.74 & 1.68 & 5.75 & 2.29 \\
S30-S6-V11 & & 3.82 & 1.72 & 5.90 & 2.35 \\
S30-S6-V13 & \multirow{2}{*}{ SF30-SF6 } & 4.46 & 2.01 & 6.78 & 2.70 \\
S30-S6-V15 & (Hybrid) & 5.17 & 2.33 & 7.76 & 3.09 \\
S30-S6-V20 & & 5.85 & 2.64 & 8.75 & 3.49 \\
S30-S6-V25 & & 6.11 & 2.75 & 9.61 & 3.83 \\
S30-S6-V30 & & 5.95 & 2.68 & 9.25 & 3.69 \\
P0 & Plain concrete & 2.22 & 1.00 & 2.51 & 1.00 \\
\hline
\end{tabular}

Notice) $\sigma_{f c r}:$ first crack strength, $\sigma_{f u} *$ flexural strength

$\sigma_{C P^{* *}}$ : first crack strength of plain concrete, $\sigma_{B P^{* *}}$ flexural strength of plain concrete

From these curves, two polygonal lines were drawn, and the first crack load was represented as the point of intersection of the two lines. This thought was used so that the inclination straight line can be changed, in times when materials changed due to other conditions, by crack initiation and so on.

On the other hand, in this research, making comparisons to the results of the first crack load by the detection of the fiber scope installed by the notch and that of the $\operatorname{LogP}-\log \delta$ method, almost the same results were obtained. From the results, the LogP-Log $\delta$ method has been reasonable for obtaining the first crack load. For the investigation of increased first crack strength and flexural strength, the strength ratio of each series (strength of FRC: strength of plain concrete) was obtained. In case of HFRC, up to $2.5 \%$ of the total fiber contents, increased more in the total fiber contents, the first crack strength and flexural strength. Investigating in detail, from $1.5 \%$ to $2.0 \%$ of the total fiber contents, the first crack strength increased by $13.2 \%$ and flexural strength increased to $12.8 \%$. However, from $2.0 \%$ to $2.5 \%$ of the total fiber contents, the first crack strength increased to $5.0 \%$ and flexural strength increased to $9.8 \%$, and it was shown that the increase rate of the strength decreased. The peak value in the total fiber contents was $2.5 \%$ where strength of the total fiber contents for $3.0 \%$ was lower than that of the total fiber contents for $2.5 \%$. For this, it is thought that the peak value is changed by the mixing condition by $\mathrm{W} / \mathrm{C}, \mathrm{S} / \mathrm{a}$, and condition of selection by AE agent etc. With regards to that and for the purpose of this research, the peak value was maintained at $50 \%$ that of $\mathrm{W} / \mathrm{C}$ and $60 \%$ for $\mathrm{S} / \mathrm{a}$, and in case of the $3.0 \%$ of the total fiber contents, it had a tendency of decreasing the workability and dispersion of fibers than that of $2.5 \%$ of the total fiber contents. In situations whereby the behavior of the total fiber contents for $3.0 \%$ differs from the general tendency, the experimental results were excluded. The law of mixture by concrete matrix and 
volume contents of fiber for the reinforce effect by the fibers is always used. In this research, extending for this the Eq. (1) including the aspect ratio $(l / d)$ of fibers was used.

$$
\sigma_{C}=\alpha_{1} \sigma_{m} V_{m}+\alpha_{2} \sigma_{f} V_{f}(l / d)
$$

Where, $\sigma_{C}$ is composites, $\sigma_{m}$ is matrix strength and $\sigma_{f}$ is stress by fibers, $V_{f}$ is fiber contents, and $V_{m}$ is $1-V_{f}$.

It was very difficult deciding $\sigma_{f}$, that is, initiations of cracks are propagated through the weakest section of structures and propagates the direction of stress concentration (cracks detoured along the shapes of fibers, or propagated by bonding fracture, and broke fibers themselves sometimes. These are shown in Figure 4). Thus, it was very difficult deciding unilaterally whether $\sigma_{f}$ is tensile strength or bonding strength.

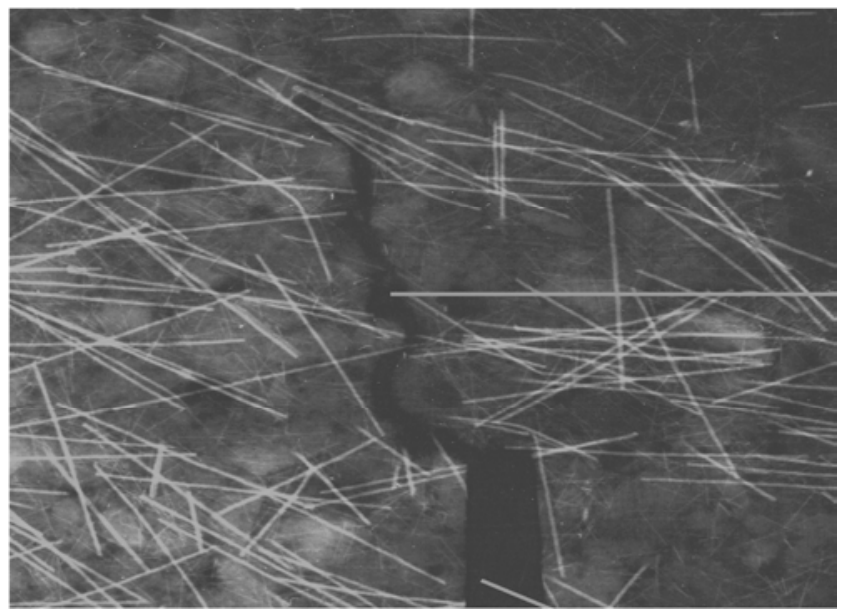

Figure 4. Aspects of the crack propagation using X-ray.

For fibers used in this research, the minimum limit length of fiber, which cut in matrix, $30 \mathrm{~mm}$-fiber is calculated as $25 \mathrm{~mm}$, and $6 \mathrm{~mm}$-fiber, is calculated as $5 \mathrm{~mm}$. From those results, it was thought that fibers are cut. But considering the effective bonding length for fiber orientation and crack, it is assumed that fiber is pulled, therefore it could not decide $\sigma_{f}$, at once. In this research, it is considered that $\sigma_{f}$ is decided by the condition of $V_{f}, l / d$, etc. So $\sigma_{f}$ is included in $\alpha_{2}$. This conception is applied in the analysis of $R$. N. Swamy, and Swamy calculated the first crack strength and flexural strength by the regression analysis from the change of fiber contents, fiber shapes, curing method and cement types. [14]

In Swamy's equation, $\sigma_{f}$ was corresponding to the bond strength of fiber; $\sigma_{f}$ is finally expressed as the assimilated type in $\alpha_{2}$. In Swamy's equation, $\alpha_{1}=0.843$ for the first crack strength and $\alpha_{2}=0.97$ for the flexural strength were used. But in this research, it is thought that $\sigma_{m}$ is not changed, and the share of strength is proportioned to $V_{m}$. Therefore, $\alpha_{1}=1$ for the coefficient of matrix was considered, and the $\alpha_{2}$ including the share of stress of fiber by the least square method from the experimental values was calculated

First crack strength $\left(\sigma_{f c r}\right)$.

SF30 series

$$
\sigma_{f c r}=\sigma_{m} V_{m}+2.55 V_{f 1}\left(l_{1} / d_{1}\right)
$$

SF6 series

$$
\sigma_{f c r}=\sigma_{m} V_{m}+3.15 V_{f 2}\left(l_{2} / d_{2}\right)
$$

SF30-SF6 series (Hybrid)

$$
\begin{gathered}
\sigma_{f c r}=\sigma_{m} V_{m}+\xi_{1}\left[2.55 V_{f 1}\left(l_{1} / d_{1}\right)+3.15 V_{f 2}\left(l_{2} / d_{2}\right)\right] \\
\xi_{1}=1.13
\end{gathered}
$$

Where, $\xi_{1}$ is considered as the coefficient of the hybrid effect for the first crack strength.

Flexural strength $\left(\sigma_{f u}\right)$.

SF30 series

$$
f_{u}=\sigma_{m} V_{m}+4.95 V_{f 1}\left(l_{1} / d_{1}\right)
$$

SF6 series

$$
\sigma_{f u}=\sigma_{m} V_{m}+2.40 V_{f 2}\left(l_{2} / d_{2}\right)
$$

SF30-SF6 series (Hybrid)

$$
\begin{gathered}
\sigma_{f u}=\sigma_{m} V_{m}+\xi_{2}\left[4.95 V_{f 1}\left(l_{1} / d_{1}\right)+2.40 V_{f 2}\left(l_{2} / d_{2}\right)\right] \\
\xi_{2}=1.22
\end{gathered}
$$

where, $\xi_{2}$ is considered as the coefficient of the hybrid effect for the flexural strength.

The comparison results between the experimental value and the calculated value of strength by Eq. (2) (9) is shown in Figure 5. As seen in Figure 5, the high correlation between the experimental value and the calculated value of strength is shown. Figure 6 shows the relationship between the total fiber contents and the strength. In case of the same fiber contents, the strength of the HFRC was higher than that of FRC.

For single fiber reinforcement, SF-30 series is higher than SF-6 series (in first crack strength). While SF-6 series was higher than SF-30 series in flexural strength. It was known to the deep relation to increase the first crack strength by adding the micro fiber and to increase the flexural strength by adding the macro fiber. In case of the hybrid fiber reinforcement, compared to the single fiber reinforcement, the mean value in first crack strength was increased by $9 \%$, and $15 \%$ of mean value in flexural strength. These results represent the hybrid effect.

\subsection{Crack Resistance}

(1) Estimation of the strain energy release rate

For the effect of the fiber reinforcement to the strain energy release rate, the mixed rule by fiber contents was applied [11].

$$
G_{c}=G_{c m}+G_{c f 1}+G_{c f 2}
$$

Where, $G_{c}, G_{c m}$, and $G_{c f 1,2}$ are strain energy release rate of composites, concrete matrix, and fibers each. 


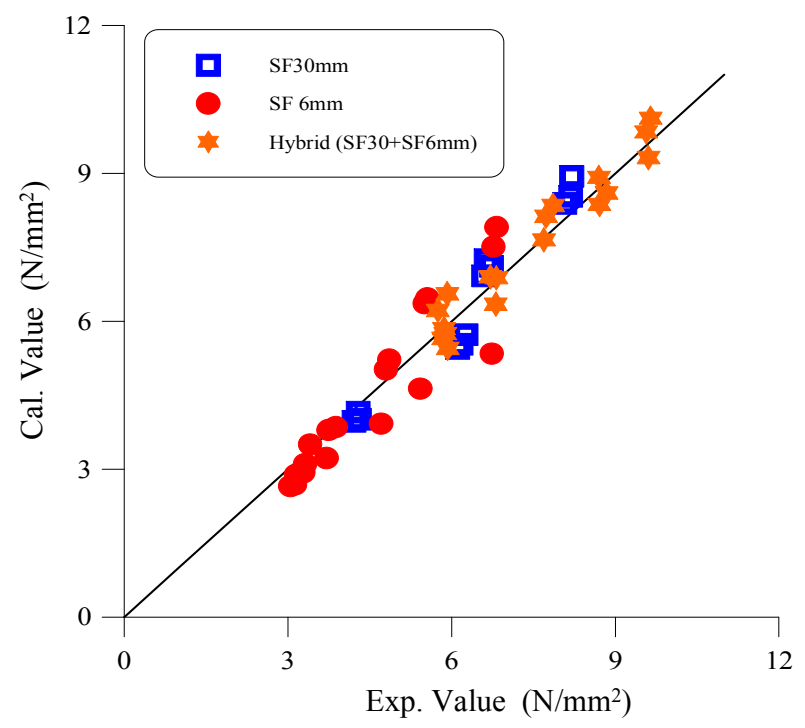

(a) First crack strength

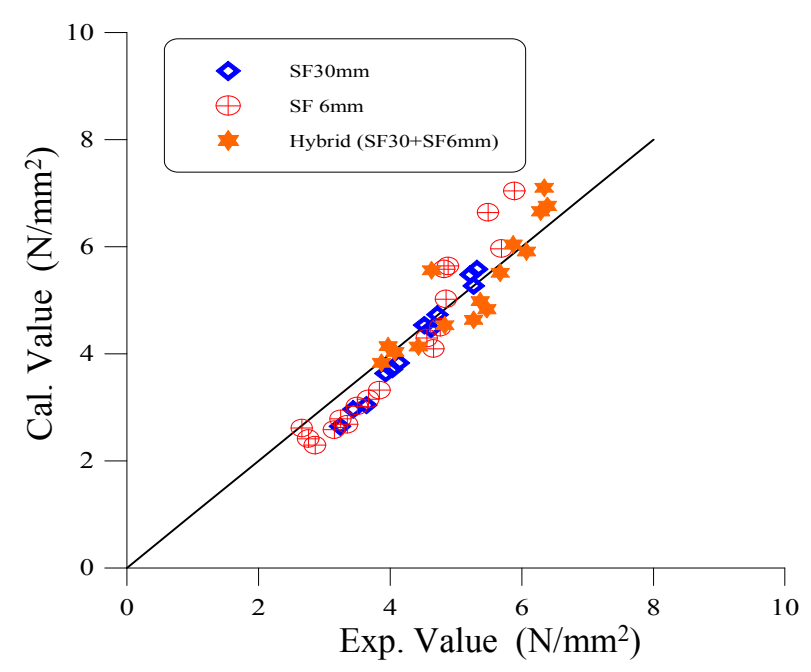

(b) Flexural strength

Figure 5. Comparison results between experimental values and theoretical values of first crack and flexural strength.

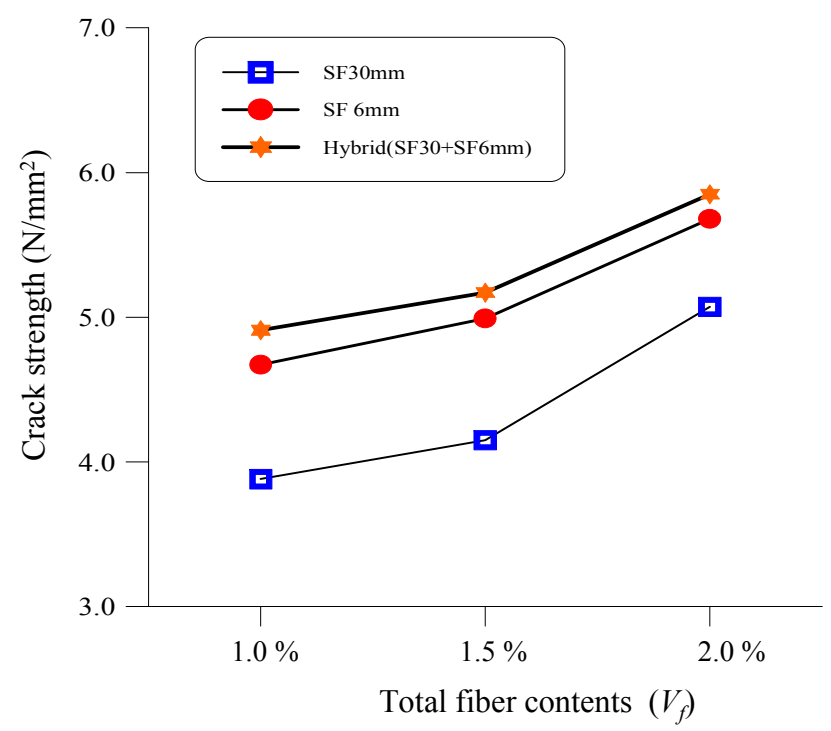

(a) First crack strength according to total fiber contents

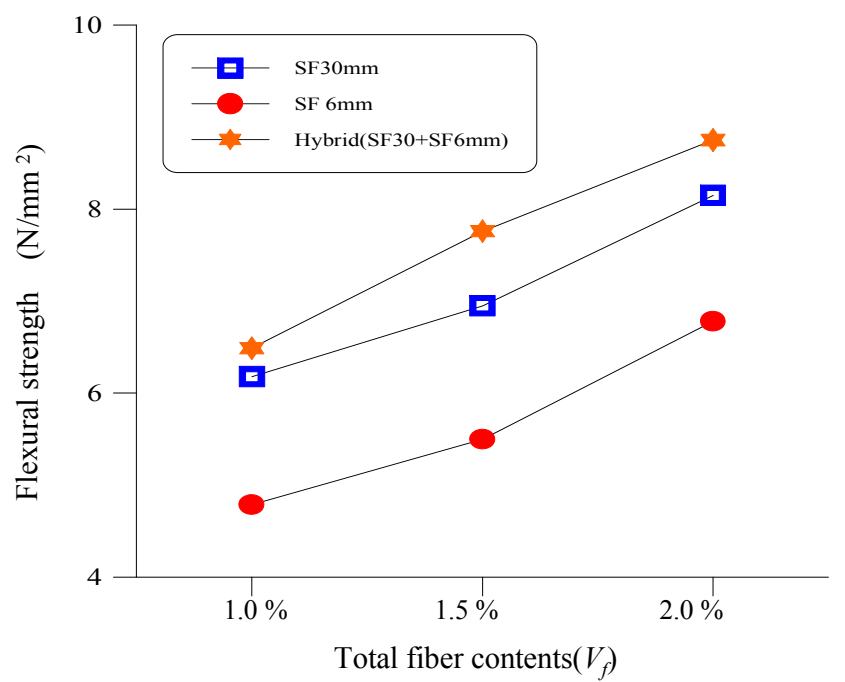

(b) Flexural strength according to total fiber contents

Figure 6. Hybrid effect.

If we let $N_{0}$ be the total numbers of fibers, we acquired the following equation:

$$
\mathrm{N}_{0}=4 \mathrm{~V}_{\mathrm{f}} / \pi \mathrm{d}^{2} \mathrm{~L}
$$

Where, $d$ is diameter of fiber, $L$ is length of fiber and $V_{f}$ is fiber contents.

Figure 7 and Figure 8 show the section of specimen and shows the numbers and orientation of fibers. From Figure 7 and Figure 8, the length of fiber looks long or short, and the different orientation. Therefore, it is understood that the orientation of fibers is 3-dimensional. [12-13, 15]

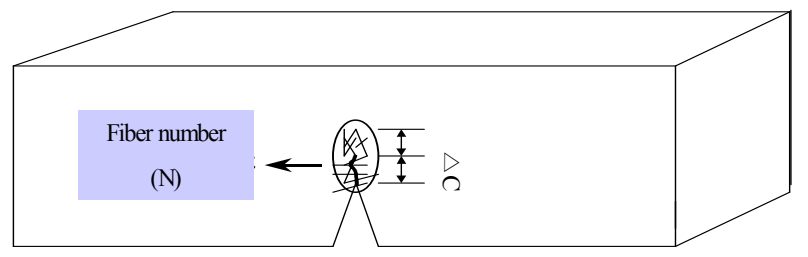

Figure 7. Fiber numbers $N$ which related to crack.

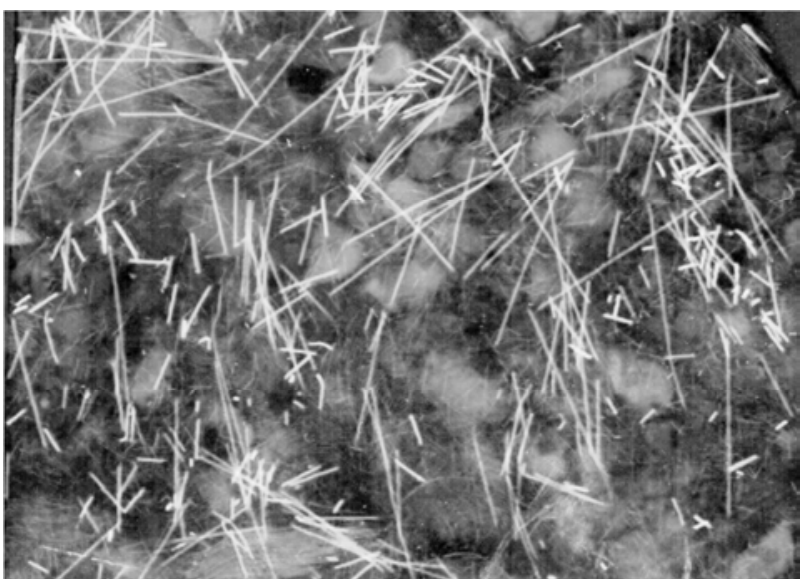

Figure 8. Aspects of fibers by $X$-ray.

The randomly fiber length $L$ could calculate the effective 
fiber length of the perpendicular direction for the tensile stress. For the orientation of fiber, there is the difference of calculating the effective fiber length, for example, 3dimensional orientation by Romualdi and 2-dimensional orientation by Parimi. [17]

In this research, the orientation of fiber is considered as 3dimensional and the orientation factor $\beta$ by Romualdi was used. Romualdi derived the equation of fiber length $L$ considering 3-dimensional randomness.[15-16]

$$
\beta=0.405
$$

The fiber numbers, $N$ which related to crack, corresponding to the fiber numbers included in the length $\Delta C$ which correspond to the unit width of specimen and the share of stress of fiber which lies in the plastic zone by stress concentration of crack tip, determined the fiber numbers within the range of $2 \triangle C$ which added to the $\Delta C$. It means that the plastic zone takes place in the crack tip by stress concentration, and the region of fibers, which shared the stress, are extended. The plastic zone $R$ calculated by Dugdale is, $R=\pi^{2} \Delta C / 8 \sigma_{y} \fallingdotseq 1.2 \Delta C$, whereas, $R=\sigma^{2} \Delta C / \sigma_{y}=\Delta C$ by Rice.[18, 19] Where, let $\sigma=\sigma_{y}, \sigma_{y}$ became the first crack strength. And in this research, the magnitude of plastic zone $R$ use $\Delta C$ by Rice.

$$
n=N_{0} \times 2 \Delta C=\left(4 V_{f} / \pi d^{2}\right) 2 \Delta C
$$

The strain energy $u_{f}$, which originated from one fiber, is represented in Eq. (14) by the stress-strain relationship.

$$
u_{f}=(1 / 2) F_{f} \varepsilon L
$$

Where, $F_{f}=\sigma_{f} \times A_{f}, \varepsilon=\sigma_{f} / E_{f}$

The length $L$ changed $\gamma_{1} \beta L$ which is converted into the effective length. Where $\beta$ is the effective orientation factor, and $\gamma_{1}$ is the diminution coefficient that corresponds to the location and the stress distribution of fibers. Therefore, $u_{f}$ was changed as follows:

$$
u_{f}=\gamma_{1} \beta \sigma_{f}^{2} A_{f} L / 2 E_{f}
$$

The strain energy $U_{f}$, which originated from $n$ fibers for unit width, are shown in the following equations: Eq. (13) and (15).

$$
U_{f}=\left(\gamma_{1} \beta \sigma_{f}^{2} A_{f} L / 2 E_{f}\right) \times n
$$

Therefore, the strain energy of fibers $G_{c f}$ are acquired from $U_{f}$ by partial differentiation to the crack length.

$$
\mathrm{G}_{\mathrm{cf}}=\partial \mathrm{U}_{\mathrm{f}} / \partial \Delta \mathrm{C}=\gamma_{1} \beta \sigma_{\mathrm{f}}^{2} L V_{\mathrm{f}} / \mathrm{E}_{\mathrm{f}}
$$

As described in the preceding chapter, the stress of fiber $\sigma_{f}$ is very difficult to examine experimentally. So, let $\sigma_{f}$ change the bonding stress $\tau_{f}$ by the state of the force equilibrium.

$$
\sigma_{f}=4 \tau_{f} l / d
$$

Where, $\tau_{f}$ is the bonding stress, $l$ is the effective bonding length. By Eq. (18) if we substitute Eq. (17), we will obtain the following:

$$
G_{c f}=16 \gamma_{1} \beta \tau_{f}^{2} l V_{f} / E_{f} d^{2}
$$

On the other hand, from the relation of the crack location, the length $L$ is used as the average length, $\beta L / 4$ which changes from 0 to $\beta L / 2$, and finally, $L$ has become $\gamma_{2} \beta L / 4$ by considering the variation coefficient $\gamma_{2}$. Finally we propose $G_{c f}$ which is a newly derived formula for the strain energy release rate of fiber reinforced concrete.

$$
G_{c f}=\gamma_{1} \gamma_{2}^{2} \beta^{3} \tau_{f}^{2} L^{3} V_{f} / E_{f} d^{2}
$$

While, $\gamma_{1} \gamma_{2}^{2}$ in Eq. (20) is an unknown quantity, (though it is thought to be about 1 ), and it was very difficult to examine the $\tau_{f}$ directly. In this research, $\tau_{f}$ is still consisting of an unknown quantity; if we let the total of the unknown quantity to be $\gamma$,

$$
G_{c f}=\gamma \beta^{3} L^{3} V_{f} / E_{f} d^{2}
$$

(2) The critical strain energy release rate $\left(G_{c}\right)$

In this research, the critical strain energy release rate for each of the series using the first crack strength by the experimental results was calculated and then compared with the theoretical results (as shown in the preceding chapter) The strain energy release rate which was used usually is as follows. [20]

$$
G=\left(\sigma^{2} \pi a / E\right) \times \kappa
$$

Where, $\kappa$ is the compensation factor according to $a / H$ (depth of notch/height of specimen). In this research, the $\kappa$ is 1.12. $\sigma$ is the first crack strength which is shown in Table 4. $E$ is the elastic modulus of plain concrete and fiber reinforced concrete.

According to the external and inner action (by working about the external force and the thermal inclination to a potential defect of the material), cracks were initiated and propagated. When the strain energy release rate $(G)$ exceeds critical strain energy release rate $\left(G_{c}\right)$, cracks initiate and propagate. Therefore, it will be effective to evaluate the crack resistance based on $G_{c}$. The result of the critical strain energy release rate of each series by the experiment is shown in Table 5. From Table 5, as in the case of the fiber reinforced concrete, the more increase in fiber contents in the range of $0.5 \% \sim 2.0 \%$, the more increase in the critical strain energy release rate. And in case of the hybrid fiber reinforced concrete, a high result of strain energy release rate in $2.5 \%$ of the total fiber contents tends to be better than that of $3.0 \%$ of the total fiber contents. Thus, the maximum value of the strain energy release rate in $2.5 \%$ is shown.

Table 5. Critical strain energy release rate.

\begin{tabular}{lllll}
\hline Specimen & Series & $\begin{array}{l}\text { Theoretical } \\
\text { values }\left(\mathbf{G}_{\mathbf{T}}\right)\end{array}$ & $\begin{array}{l}\text { Experimental } \\
\text { values }\left(\mathbf{G}_{\mathbf{E}}\right)\end{array}$ & $\mathbf{G}_{\mathbf{T}} / \mathbf{G}_{\mathbf{E}}$ \\
$\mathbf{( \mathbf { N } / \mathbf { m m } )}$ & 0.043 & 0.049 & 1.14 \\
\hline S30-V05 & & 0.065 & 0.065 & 1.00 \\
S30-V10 & \multirow{2}{*}{ SF30 } & 0.087 & 0.085 & 0.98 \\
S30-V15 & & 0.109 & 0.109 & 1.00 \\
S30-V20 & & 0.028 & 0.032 & 1.14 \\
S6-V01 & \multirow{2}{*}{ SF6 } & 0.038 & 0.043 & 1.13 \\
S6-V03 & & & & \\
\hline
\end{tabular}




\begin{tabular}{lllll}
\hline Specimen & Series & $\begin{array}{l}\text { Theoretical } \\
\text { values }\left(\mathbf{G}_{\mathbf{T}}\right) \\
(\mathbf{N} / \mathbf{m m})\end{array}$ & $\begin{array}{l}\text { Experimental } \\
\text { values }\left(\mathbf{G}_{\mathbf{E}}\right)\end{array}$ & $\mathbf{G}_{\mathbf{T}} / \mathbf{G}_{\mathbf{E}}$ \\
$\mathbf{( N / m m )}$ & \\
\hline S6-V05 & & 0.049 & 0.055 & 1.12 \\
S6-V10 & & 0.075 & 0.087 & 1.16 \\
S6-V15 & & 0.101 & 0.093 & 0.92 \\
S6-V20 & & 0.127 & 0.126 & 0.99 \\
S30-S6-V11 & & 0.079 & 0.073 & 0.92 \\
S30-S6-V13 & & 0.090 & 0.086 & 0.96 \\
S30-S6-V15 & SF30-SF6 & 0.101 & 0.113 & 1.12 \\
S30-S6-V20 & (Hybrid) & 0.131 & 0.132 & 1.01 \\
S30-S6-V25 & & 0.146 & 0.153 & 1.05 \\
S30-S6-V30 & & 0.159 & 0.142 & 0.89 \\
P0 & Plain concrete & 0.023 & 0.023 & 1.00 \\
\hline
\end{tabular}

Notice) $G_{c m}{ }^{*}$ : Critical strain release rate of plain concrete

In Figure 9 the hybrid fiber reinforcing effect is shown. From Figure 9, (comparing the same fiber contents), hybrid fiber reinforced concrete has more high critical strain energy release rate than that of the fiber reinforced concrete. In case of the fiber reinforced concrete, SF6 series has more high critical strain energy release rate than that of SF30 series. That is, the estimation of the critical energy release rate is used by the first crack strength, with regards to this the micro fiber is more effective on the improvement of the first crack strength than that of macro fiber. The rate of increase of strain energy release rate for hybrid fiber reinforced concrete has become about $10 \%$ than that of the SF6 series.

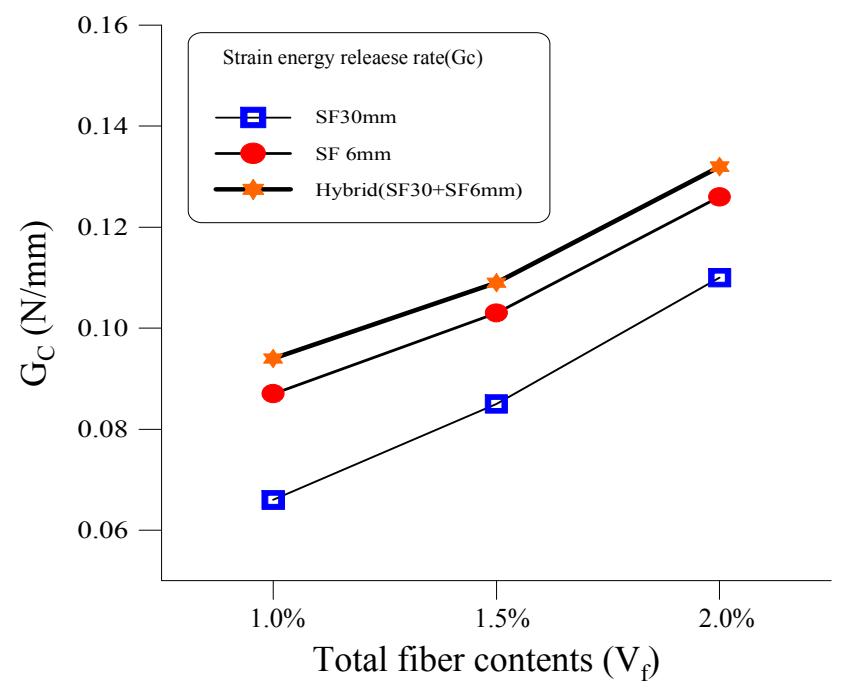

Figure 9. $G_{c}$ according to the hybrid effect.

(3) Comparison results of the strain energy release rate between experimental and theoretical value

Considering the results of the strain energy release rate between experimental value and theoretical value by Eq. (21), we propose the new formula which is to be related to the strain energy release rate for fiber reinforced concrete. [20]

$$
\begin{aligned}
& G_{c f l}=G_{c m}+\left(7.52 L^{3} V_{f} / E_{f} d^{2}\right) ; \text { for SF30 series } \\
& G_{c f 2}=G_{c m}+\left(16.86 L^{3} V_{f} / E_{f} d^{2}\right) ; \text { for SF30 series }
\end{aligned}
$$

Where, the unknown quantity, $\gamma$ is obtained by the least square method.

$$
\begin{gathered}
G_{c}=G_{c m}+\xi_{3}\left(G_{c f 1}+G_{c f 2}\right) ; \text { for SF30-SF6 series (hybrid) } \\
\xi_{3}=1.25
\end{gathered}
$$

Where, $\xi_{3}$ is the hybrid effect to the critical strain energy release rate.

On the other hand, comparison results of the strain energy release rate between the experimental value and theoretical value by Eq. (23) (25) is shown in Table 6 and Figure 10. As seen in Figure 10, the close relation between the experimental value and theoretical value for the strain energy release rate is shown.

Table 6. Comparison results of the strain energy release rate between experimental and theoretical value.

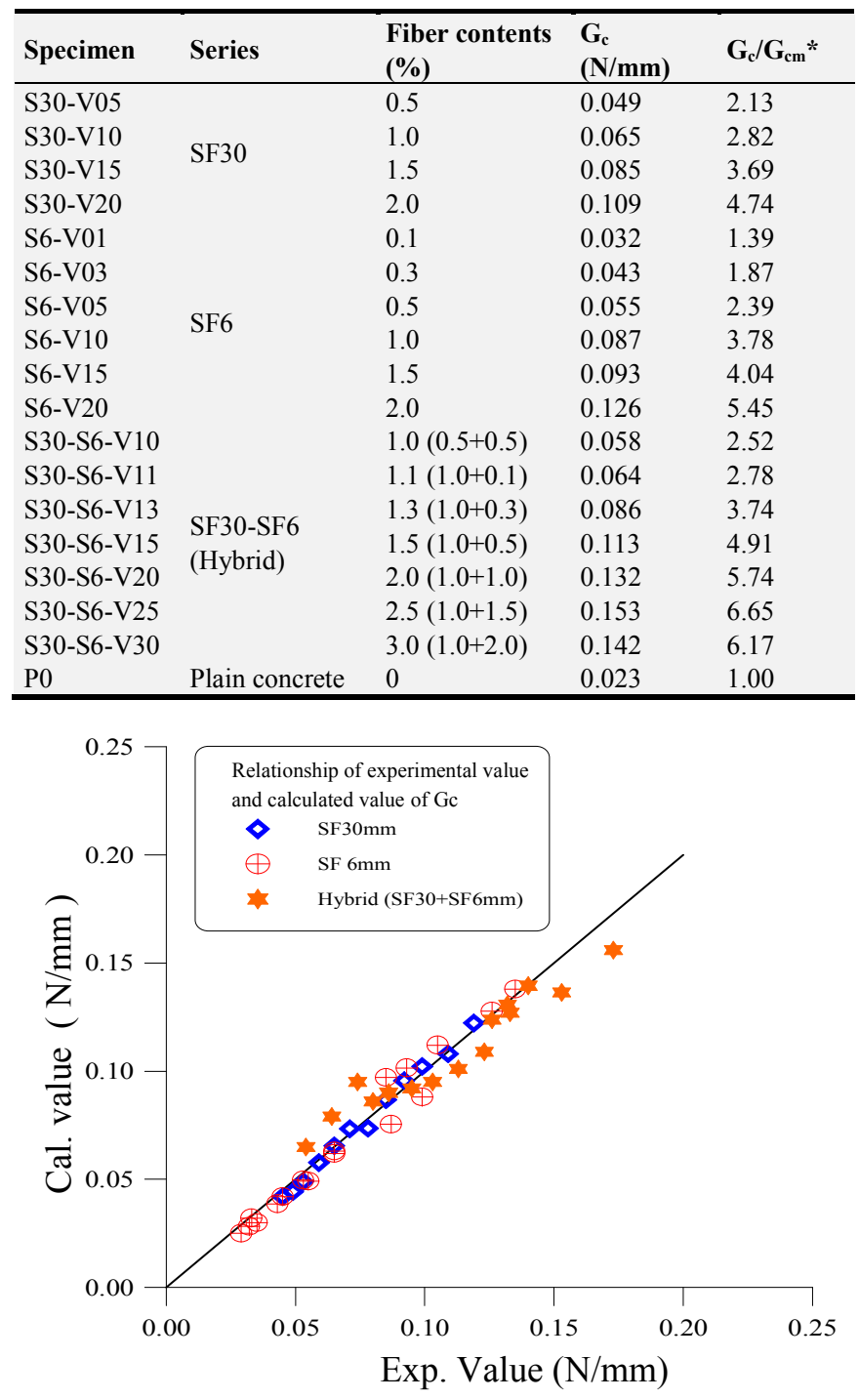

Figure 10. Experimental and calculated value of the strain energy release rate $(G c)$.

\section{Conclusions}

In this research, the crack resistance of concrete was investigated using the notched specimen by the 4-point bending test for the fiber reinforced concrete and hybrid fiber reinforced concrete (adding the macro and micro fibers). The 
general conclusions obtained are as follows.

1) In case of the same total fiber contents $\left(V_{f}: 1.0 \%, 1.5 \%\right.$, $2.0 \%)$, comparing the hybrid fiber reinforced concrete and fiber reinforced concrete by load-deflection curves and loadCMOD curves, hybrid fiber reinforced concrete increased more in first crack strength, maximum load and toughness than that of fiber reinforced concrete.

2) In case of the fiber reinforced concrete, first crack strength increased more in the SF-6 series using the micro fiber than in the SF-30 series (using the macro fiber). Flexural strength is higher in SF-30 series than in the SF-6 series. In case of the first crack strength, hybrid fiber reinforced concrete increased 9\% than that of the SF-6 series, and in case of the flexural strength, SF- 6 increased $15 \%$ more than that of the SF-30 series.

3 ) Using the mixed rule by the volume fraction of concrete and fiber, we proposed the theoretical equation of the first crack strength and flexural strength for hybrid fiber reinforced concrete and fiber reinforced concrete, and a deep correlation between experimental values and theoretical values was shown. $\xi_{1}$ which is considered the coefficient of the hybrid effect was 1.13 for the first crack strength and $\xi_{2}$ was 1.22 for the flexural strength.

4) To the investigation of the crack resistance of concrete, we obtained the new theoretical equation of the critical strain energy release rate for the hybrid fiber reinforced concrete, and a deep correlation between experimental value and theoretical value was shown. Where, hybrid effect coefficient, $\xi_{3}$ was 1.25 .

5) Though in this research, total fiber contents $2.5 \%$ (SF30-1.0\% + SF6-1.5\%) showed the maximum values in the strength and crack resistance, an investigation of the totally mechanical behavior needs more widely range of experiment.

\section{Acknowledgements}

This work is supported by the Korea Agency for Infrastructure Technology Advancement (KAIA) grant funded by the Ministry of Land, Infrastructure and Transport (Grant No. 19PO QW-B152342-01).

\section{References}

[1] Fujita K. and Saeki N. (1978), "Crack initiation and propagation of concrete," J. of Japan Concrete Institute, 16 (11), 1-9.

[2] Batson G. B., et al. (1973), "State-of-the-art report on fiber reinforced concrete," $S P-44, A C I, 535-550$.
[3] Horiguchi T., et al. (1997), "Hybrid effects of fiber reinforced concrete on fracture toughness," $S P-172, A C I, 535-548$.

[4] Rossi P. (1997), "High performance multimodal fiber reinforced cement composites," J. Mat., ACI, 94 (54), 478-483.

[5] Kim N. W., et al. (1998), "Crack resistance of hybrid fiber reinforced concrete," J. Japan Cement Association, 48 (1), 396-397.

[6] Banthia N., et al. (1996), "Fracture toughness of micro-fiber reinforced cement composites," Cement and Concrete Research, 18 (1), 251-269.

[7] Mihashi H., et al. (1999), "Discussion on standard evaluation method for tension softening properties of concrete," Concrete Research and Technology, 10 (1), 56-63.

[8] Murakami S., et al. (1995), "Tension softening and size effect of steel fiber reinforced concrete,", J. Japan Cement Association, 45 (1), 21-29.

[9] Mihashi H. and Rokugo K. (1997), "Fracture mechanics of concrete - attraction \& prospect," J. of Japan Concrete Institute, 37 (9), 4-10.

[10] Japan Society of Civil Engineers. (1997), "Size Effect and Tension Softening Curves," Concrete Technology Series, 18 (1), 67-89.

[11] Kim N. W., et al. (1998), "Effect of the crack control of the hybrid fiber reinforced concrete using micro fibers," Proceedings of Korea-Japan Joint Symposium on Structural Material Engineering, 1 (1), 68-77.

[12] Kim N. W., et al. (1998), "Fracture behavior of hybrid fiber reinforced concrete," Proceeding of JSCE, 47 (1), 942-943.

[13] Kim N. W., et al. (1999), "Crack resistance of hybrid fiber reinforced concrete at early age," Proceedings of JSCEHokkaido Chapter, V-5, 444-449.

[14] Swamy R. N. (1973), "The mechanics of fiber reinforced of cement matrices," SP44-1, ACI, 1-28.

[15] Buckley E. L. (1973), "Prediction of the modulus of rupture of fiber reinforced portland cement mortar and concrete," SP44-9, ACI, 163-175.

[16] Romualdi J. P. (1968), "Prevention and control of cracking by use of short random fibers," SP-20, ACI, 10-22.

[17] Parimi S. R. (1973), "On the fracture toughness of fiber reinforced concrete," SP44-4, ACI, 79-92.

[18] Dugdale D. S. (1960), Journal of Mechanics in Physics \& Solids, 8 (1), 100-104.

[19] RICE J. R. (1966), International Journal of Fracture Mechanics, 2 (2), 426-447.

[20] GRIFFITH A. A. (1921), "The phenomena of rupture and flow in solids," Trans. of Royal Society of London, A221, 163-198. 